\title{
Efficacy and Safety of Carbetocin for the Prevention of Primary PPH During Caesarean Section: An Open Label Single Arm Study
}

\author{
RAZZAQUE S ${ }^{1}$, KHAN AD $^{2}$
}

\begin{abstract}
Background: The risk of postpartum haemorrhage is much higher for women undergoing caesarean section, particularly in developing countries where the majority of operations are carried out as an emergency procedure. Postpartum haemorrhage is the leading cause of maternal mortality worldwide. Around $67-80 \%$ of cases are caused by uterine atony. Preventive measures include prophylactic drugs use to aid uterine contraction after delivery, thus avoiding severe blood loss and reducing maternal morbidity and mortality. Carbetocin a synthetic analogue of oxytocin is currently indicated for prevention of uterine atony after delivery by caesarean section in spinal or epidural anaesthesia.

The Aim of Study: To see the efficacy and safety of Carbetocin for the prophylaxis of PPH during caesarean section.

Patients and Methods: An open label single arm clinical trial was conducted in the Bagerhat Sadar Hospital, Bangladesh over a period of six months from May 2017 to October 2017. Ninety patients who had got admitted in Bagerhat Sadar Hospital, undergoing cesarean section at term were selected. Each patient obtained a single dose of 100 microgram carbetocin intravenously during cesarean section, immediately after the delivery of the baby and prior to the delivery of the placenta. Outcome measures such as primary $\mathrm{PPH}$, blood loss was observed and measured by weighing sanitary napkin observed for six hours. Need for additional uterotonic drug, additional blood transfusion as well as adverse effects were all documented.
\end{abstract}

Results: Massive blood loss occurred only in 3.3\% patients. Among the study population $96.7 \%$ patients did not need any additional uterotonics. No patient had developed fever, arrhythmia, pulmonary edema, tremor, abdominal pain and pruritus. Only 2.2\% had nausea, only 3.3\% had hypotention, only 3.3\% had vomiting and only $2.2 \%$ had headache which was not statistically significant. Only 4.4\% patients developed PPH.

Conclusion: Carbetocin appears to be an effective new drug for the prophylaxis of postpartum hemorrhage in cesarean section.

Key Words: Carbetocin, Primary PPH.

Introduction:

Postpartum haemorrhage (PPH) is one of the major contributors to maternal mortality and morbidity worldwide. If a woman bleeds after childbirth and does not receive immediate medical care, she may die within two hours. So the biggest killer is obstetric hemorrhage and the most frequent cause is uterine atony with an estimated mortality rate of 140,000 per year or 1 maternal death every 4 minutes. ${ }^{1} \mathrm{PPH}$ complicates $11 \%$ of deliveries worldwide and is annually responsible for $1,32,000$ maternal deaths ${ }^{2}$. In developing countries, mortality from $\mathrm{PPH}$ remains

1. Dr. Sahana Razzaque, Associate Professor, Department of Gynecology and Obstetrics, Khulna Medical College and Hospital, Khulna, Bangladesh.

2. Dr. Abu Dawood Khan, Junior Consultant, Gynae, Bagerhat Sadar Hospital, Kochua, Bagerhat.

Address of Correspondence: Dr. Sahana Razzaque, Associate Professor, Department of Gynecology and Obstetrics, Khulna Medical College and Hospital, Khulna, Bangladesh. Mob.01713425503, Email - sahanarazzaque@gmail.com 
high $^{3}$. In low income setting, PPH accounting for $30 \%$ of maternal death ${ }^{4}$, while in Bangladesh it is $31 \%{ }^{5}$. All pregnant women are at risk of complications during the $3^{\text {rd }}$ stage of labor ${ }^{6}$. Maternal risk factors contribute to the development of postpartum hemorrhage ${ }^{7}$. For women undergoing delivery by cesarean section, there is an increased risk of postpartum hemorrhage compared to vaginal delivery ${ }^{8}$. Primary PPH is the most common obstetric hemorrhage and is defined by the World Health Organization as the loss of blood estimated to be $>1000 \mathrm{ml}$ from the genital tract after caesarean section within 24 hours of delivery. ${ }^{9}$ .If obstetric hemorrhage is not managed efficiently and effectively, this will lead to shock, hemostatic failure from disseminated intravascular coagulation and ultimately death ${ }^{10}$.So use of an effective uterotonic drug for prevention of uterine atony as well as PPH is highly recommended .

Conventional uterotonics like oxytocin is used for preventing PPH but it has some limitations like shorter half life ${ }^{11}$, less contraction time and more side effects like fluid overload, convulsion, arrhythmia and pulmonary edema. In addition, the ergot alkaloids cannot be used in $10-15 \%$ of women who have gestational hypertension ${ }^{12}$. Further, oxytocin and ergot preparation require protection against light to preserve its effectiveness and stability ${ }^{13}$. In our country cold chain is not properly maintained for oxytocin. So, there is a chance of its effectiveness and stability problems. As a result treatment failure may occur. Bleeding due to uterine atony, can be prevented by an effective uterotonic agent ${ }^{14}$. Till now it is recommended that Oxytocin should be used as uterotonic agent either in the form of intramuscular injection or intravenous infusion.

Carbetocin is a long-acting synthetic analogue of oxytocin with agonist properties ${ }^{15,16}$. Carbetocin has prolonged duration of action (approximately 1 hour) which ensures more contraction time and less adverse effect ${ }^{17,18}$. The clinical and pharmacological properties of carbetocin are similar to those of naturally occurring oxytocin. Carbetocin binds to oxytocin receptors present on the smooth musculature of the uterus, resulting in rhythmic contractions of the uterus, increased frequency of existing contractions and increased uterine tone ${ }^{13}$. A single dose of carbetocin acts up to 16 hours in comparison to intravenous oxytocin infusion regarding the increase in uterine tone and the reduction of the risk of $\mathrm{PPH}$ in caesarean section ${ }^{12}$.Moreover, carbetocin ensures more effective contraction and less adverse effect like headache, tremor, hypotension, nausea, abdominal pain, and pruritus ${ }^{13}$. Several data of literature suggest that prophylactic administration of carbetocin may be a good alternative to oxytocin to prevent postpartum haemorrhage ${ }^{19}$.

We had conducted this clinical study to evaluate the efficacy and safety of Carbetocin for the prophylaxis of $\mathrm{PPH}$ during caesarian section.

\section{Materials and Methods:}

An open label single arm clinical frial was done from May'2017 to October'2017 in the Department of Gynecology and Obstetrics, Bagerhat Sadar Hospital,Bagerhat, Bangladesh. Ninty pregnant women were included in this study. The participants were enrolled in the study after fulfilling the inclusion and exclusion criteria. A written informed consent was taken from eligible women on admission. Inclusion criteria were women with a single pregnancy undergoing caesarean delivery. Indication of cesarean section were cephalopelvic disproportion, malpresentation-eg, breech, transverse lie, previous history of cesarean section, fetal distress, very low birth weight and failed induction of labour. Exclusion criteria were placenta previa, multiple gestation, placental abruption (determined by history and ultrasound report) hypertensive disorders in pregnancy, preeclampsia, and known case of cardiac, renal, liver diseases, epilepsy, moderate anemia and unwilling to participate in the study. Study medication was a single dose of 100 microgram carbetocin intravenously by anesthetists during cesarean section, immediately after the delivery of the baby and prior to the delivery of the placenta.

Primary outcome is primary postpartum haemorrhage (PPH) defined as blood loss from genital tract of $1000 \mathrm{ml}$ or more within 24 hours in case of caesarean section. Blood loss was estimated by the surgeon in the usual way such as visual estimation and amount of aspirated blood ${ }^{16}$. The secondary outcomes were massive blood loss, defined as blood loss of $50 \%$ of circulating blood volume within a 3-hour period, need for additional uterotonic therapy that means when single unit of duratocin did not control of primary PPH we used misoprostol as an additional uterotonics, additional 
blood transfusion as well as adverse effects within 24 hours of delivery. Uterine tone was evaluated by palpation. Administration of additional uterotonics was the decision of the investigator.

Analysis was performed by using a computer based statistical program SPSS (Statistical Package for Social Sciences) version 23. Quantitative data were expressed as means $\pm S D ; 95 \%$ confidence interval was calculated and $p$ value of $<0.05$ was considered as significance.

\section{Result:}

A total of 100 pregnant women with a single ton pregnancy were initially recruited for inclusion in this study; 10 cases were excluded (4 had pre-eclampsia, 2 eclampsia, 1 multiple gestation, 3 severely anaemic). Thus 90 women formed the final study group and were included in the final analysis. Mean age of study population were $24.5 \pm 4.48$ years (Table I). Among the study patients $96.7 \%$ (87) had mild anemia. Mean systolic BP of patients were $110 \pm 1.17$ $\mathrm{mm}$ of $\mathrm{Hg}$ and Diastolic BP were $70 \pm 8.5 \mathrm{~mm}$ of $\mathrm{Hg}$. Mean gestational age at delivery were $38.2 \pm 1.12$ weeks (Table-I). Massive blood loss occurred in 3.3\% patients and additional uterotonic needed for $3.3 \%$ patients (Table-II). There were no major adverse effects observed in this study(Table III). Only 4.4\%(4)patients had developed PPH.(Table-IV)

Table-I

Baseline characteristics of study patients $(n=90)$

\begin{tabular}{ll}
\hline Age & $24.5 \pm 4.48$ \\
Mild Anemia & $96.7 \%(87)$ \\
Systolic BP & $110 \pm 1.17 \mathrm{~mm}$ of $\mathrm{Hg}$ \\
Diastolic BP & $70 \pm 8.5 \mathrm{~mm}$ of Hg \\
Gestational Age & $38.2 \pm 1.12$ weeks \\
Primigravida & $44.4 \%(40)$ \\
Multi-gravida & $55.5 \%(50)$ \\
\hline
\end{tabular}

Table-I. Data were presented as mean \pm SD. Here Mean age $24.5 \pm 4.48$ years, Mild anemia $96.7 \%$, Mean systolic BP $110 \pm 1.17 \mathrm{~mm}$ of $\mathrm{Hg}$,Diastolic BP $70 \pm 8.5 \mathrm{~mm}$ of $\mathrm{Hg}$, Gestational age $38.2 \pm 1.12$ weeks, primigravida $44.4 \%$ and multi-gravida $55.5 \%$.

Table-II

Outcome during Labour $(n=90)$

\begin{tabular}{lccc}
\hline & Yes (\%) & No (\%) & P value \\
\hline Massive blood loss & $3.3 \%(3)$ & $96.7 \%(87)$ & 0.41 \\
Need for additional uterotonics & $3.3 \%(3)$ & $96.7 \%(87)$ & 0.41 \\
\hline
\end{tabular}

Table-II.Showed that massive blood loss occurred in $3.3 \%$ patients and additional uterotonic drug needed for $3.3 \%$ patients. The difference were not statistically significancy. $(P>0.05)$

Table-III

Adverse effects $(n=90)$

\begin{tabular}{lcc}
\hline Side effects & $(\mathrm{n}=90) \mathrm{n}(\%)$ & P value \\
\hline Nausea & $2.2 \%(3)$ & 0.42 \\
Vomiting & $3.3 \%(3)$ & 0.41 \\
Fever & $00 \%(0)$ & 0.50 \\
Arrhythmia & $00 \%(0)$ & 0.50 \\
Pulmonary edema & $00 \%(0)$ & 0.50 \\
Abdominal Pain & $00 \%(0)$ & 0.50 \\
Headache & $2.2 \%(3)$ & 0.42 \\
Tremor & $00 \%(0)$ & 0.50 \\
Hypotension & $3.3 \%(3)$ & 0.41 \\
Pruritus & $00 \%(0)$ & 0.50 \\
\hline
\end{tabular}

Table-III. There were no major adverse effects observed in the study population. The differences were not statistically significant. $(P>0.05)$

Table-IV

Outcome of the patient: Primary PPH $(n=90)$

\begin{tabular}{lcc}
\hline $\begin{array}{l}\text { Outcome } \\
\text { (Primary PPH) }\end{array}$ & $(\mathrm{n}=90), \mathrm{n}(\%)$ & P value \\
\hline Yes & $4.4 \%(4)$ & 0.06 \\
No & $95.6 \%(86)$ & \\
\hline
\end{tabular}

Table-IV Showed only $4.4 \%$ patients developed $\mathrm{PPH}$.P value $>0.05$, So it is not statistically significant.

\section{Discussion:}

The results of this study had shown that carbetocin is effective for the prevention of primary PPH following ceserian section. Each patient obtained a single dose of 100 microgram carbetocin intravenously during cesarean section, immediately after the delivery of the baby and prior to the delivery of the placenta. Outcome measures such as primary PPH, massive blood loss, need for additional uterotonic drug, additional blood transfusion as well as adverse effects were documented.

Reyes OA and Gonzalez GM et al. ${ }^{20}$ showed that mean age of study patient were 26.5 years. In this study mean age of study patients were $24.5 \pm 4.48$ years. Debbie-lynuy and Nelindac atherinep et al. ${ }^{21}$ showed that mean preoperative systolic BP of study patients were $117 \pm 6.8 \mathrm{~mm}$ of $\mathrm{Hg}$ and diastolic BP 
were $69 \pm 7.7 \mathrm{~mm}$ of $\mathrm{Hg}$. In this study, mean preoperative systolic BP of patients were $110 \pm 1.17$ $\mathrm{mm}$ of $\mathrm{Hg}$ and diastolic BP were $70 \pm 8.5 \mathrm{~mm}$ of $\mathrm{Hg}$. All patients were with normal blood pressure.

Reyes OA and Gonzalez $\mathrm{GM}$ et $\mathrm{al}^{20}$ also showed that the mean gestational age of study patient were 37.44 weeks which is almost similar to this study; $38.2 \pm 1.12$ weeks. They also showed that there was no significant adverse effects of the drug. In this study, there was no major adverse effects.

Sergio Rosales-Ortiz, Rogelio Perez Aguado et al. ${ }^{22}$ showed that only $1.5 \%$ patients need additional uterotonics. Manal M. E Behery et al. ${ }^{23}$ showed that none of the patient in carbetocin group required additional uterotonics. CAG. Holleboom, J. van Eyck et al. $^{24}$ also showed the comparison between carbetocin with oxytocin, prophylaxis of uterine atony with carbetocin after an elective caesarean section diminished the need for additional uterotonics by more than $50 \%$ in oxytocin group. Debbie-lynuy et al. ${ }^{21}$ showed that only $5.7 \%$ patients were need for additional uterotonics in carbetocin group. In this study, $3.3 \%(3)$ patients were required additional uterotonic.

Ahmed Mohamed Maged et al. ${ }^{25}$ also showed the occurrence of $\mathrm{PPH}$ were $4 \%$ in their study. In our study, occurrence of PPH was only in $4.4 \%(4)$ patients.

Primary postpartum haemorrhage (PPH) is the most common form of major obstetric hemorrhage ${ }^{26}$. It is the most common cause of maternal morbidity in developed countries and a major cause of death worldwide 27,28 . The most common point at which $\mathrm{PPH}$ occurs is during the third stage of labour, when the uterus may suddenly loss its ability to contract. Around $80 \%$ of cases of postpartum hemorrhage occur due to uterine atony ${ }^{29}$. Bleeding due to uterine atony, can be prevented by an effective uterotonic drug $^{30,31}$. The promising findings suggested that carbetocin appears to be an effective new drug for the prevention of $\mathrm{PPH}$ in caesarian delivery. A single dose of 100 microgram IV carbetocin is effective for maintaining adequate uterine tone, decreases blood loss and preventing postpartum hemorrhage in women undergoing caesarian delivery. Carbetocin can be considered as a good uterotonic agent for the prevention of $\mathrm{PPH}$ in caesarian section.

\section{Conclusion:}

Carbetocin appeared to be an effective new drug for the prevention of primary $\mathrm{PPH}$ during cesarean section. Carbetocin has long half-life, which ensures more effective contraction and less adverse effects. Our limitation was sample size was small.So multicenter research is required to verify our findings.

\section{Acknowledgments:}

This study was conducted by Department of Gynecology and Obstetrics, Bagerhat Sadar Hospital, Bagerhut, Bangladesh. The research team would like to thank all doctors, health staff and patients for participating in the clinical trial.

\section{Conflict of interest:}

The authors declare that there is no conflict of interests regarding the clinical trial.

\section{References:}

1. D lynuy, N Atherinep et al: Carbetocin versus Oxytocin for the Prevention of Postpartum Hemorrhage Following Elective Cesarean Section: Rizal Medical Center Experience; Philippine Journal of Obstetrics \& Gynecology. 2013; 37 (2):71-79

2. Carroli G.,Cuesta C.,Abalos E .and Gulmezoglu A.M.: Epidemiology of postpartum haemorrhage: A systematic review.Best.Pract. Res. Clin. Obstet. Gynaecol., 22 (6): 999-1012, 2008

3. American Academy of Family Practitioners (AAFP). Advanced Life Support in Obstetrics. Syllabus Updates.Downloaded 21/05/2008 from www.aafp.org/online/en/ home/cme/ aafpcourses/clinicalcourses/also/syllabus. ht ml\#Parsys0003, 2008

4. Derman R, Kodkany BS, Goudar SS, Geller SE, Naik VA, Bellad MB, Patted SS, Patel A, Edlavitch SA, Hartwell T, Chakraborty H, Moss N.Oral misoprostol in preventing postpartumhaemorrhage in resource-poor communities: a randomised controlled trial. Lancet2006; 368:1248-53.

5. National Institute of Population Research and Training (NIPORT), MEASURE Evaluation, UNC-CH, USA, ICDDR, B., 2011

6. Smith JR. Management of Third Stage of Labor: January 6, 2012 
7. Leduc D, et al. Active management of the third stage of labor; prevention and treatment of postpartum hemorrhage. JOGC 2009; 980-92

8. Prendiville $\mathrm{W}$ and Connell MO. Active management of the third stage of labor p. 98113

9. World Health Organisation: WHO Guidelines for the Management of Postpartum Haemorrhage and Retained Placenta. http://whqlibdoc.who.int/ publications/2009/ 9789241598514_eng. pdf, 2009

10. Annette Briley and Susan Bewle: Management of obstetric haemorrhage. In: Sue Pavrod and Beverly Hunt. The Obstetric Hematology Manual. United State of America, Cambridge University Press, ISBN-13 978-0-521-86564- 7, Section 5 Chapter 13a, 2010.

11. Oyelese Y, Scorza WE, Mastrolia R, Smulian JC .Post- partum hemorrhage. Obstet Gynecol Clin N Am 2007; 34(3):421-441.

12. G Larciprete, $C$ Montagnoli, M Frigo, V Panetta $\mathrm{J}$, Prenat et al Carbetocin versus oxytocin in caesarean section with high risk of post-partum haemorrhage Med. 2013 Jan-Mar; 7(1): 12-18.

13. Werner R. Prevention of postpartum haemorrhage with the oxytocin analogue carbetocin. European Journal of Obstetrics and Gynecology and Reproductive Biology; 2009; 147 (1): 15-20.

14. Derman R, Kodkany BS, Goudar SS, Geller SE, Naik VA, Bellad MB, Patted SS, Patel A, Edlavitch SA, Hartwell T, Chakraborty H, Moss N.Oral misoprostol in preventing post partum haemorrhage in resource-poor communities: a randomised controlled trial. Lancet2006; 368:1248-53.

15. Gazi R, Quaiyum, A, Islam, M, Hossain, S, Wirtz, A,L, Saha, , N, C, Jesmin, M. Post-Partum Excessive Bleeding among Bangladeshi Women: Determinants, Perceptions, Recognition, Responses. Centre for Equity and Health Systems, icddr, Dhaka, Bangladesh. Published November 15, 2012

16. Attilakos G, Psaroudakis D, Ash J, Buchanan R, Winter C, Donald F, Hunt L, Draycott T. Carbetocin versus oxytocin for the prevention of postpartum haemorrhage following caesarean section: the results of a double-blind randomized trial. BJOG 2010; 117: 929-936

17. Tharakan $\mathrm{T}$, Jha J Randomized double blind prospective trial of active management of the third stage of labor. Arch Med Sci 2008; 4(1): 79-82.

18. Sergio RO, RP Aguado et al. Carbetocin versus oxytocin for prevention of postpartum haemorrhage: a randomized controlled trial. Published Online February 26, 2014 School of Clinical and Experimental Medicine, University of Birmingham, UK

19. MP Yuen.Oxytocic Agents for the Management of Postpartum Haemorrhage 2011; 16: 10.

20. Reyes OA, Gonzalez GM : Carbetocin versus oxytocin for prevention of postpartum hemorrhage in patients with severe preeclampsia: a double-blind randomized controlled trial. J obstet gynaecol can 2011; 33(11):1099-1104

21. D lynuy, N Atherinep et al: Carbetocin versus Oxytocin for the Prevention of Postpartum Hemorrhage Following Elective Cesarean Section: Rizal Medical Center Experience; Philippine Journal of Obstetrics \& Gynecology. 2013; 37 (2):71-79

22. $S$ R Ortiz, R P Aguado, RS Hernandez, M Castorena et al: Carbetocin versus oxytocin for prevention of postpartum haemorrhage: a randomised controlled trial; The Lancet. 2014 ;383:51

23. Manal M, El Behery, G Abbas, El Sayeda, Azza A et al: Carbetocin versus oxytocin for prevention of postpartum hemorrhage in obese nulliparous women undergoing emergency cesarean delivery.

24. CAG. Holleboom, J.VAN Eyck, SV. Koenen: Carbetocin in comparison with oxytocin in several dosing regimens for the prevention of uterine atony after elective caesarean section in the Netherlands. ArchGynecol Obstet 2013; 287:1111-1117

25. AM Maged, A Gany, A Hassan, AA Nesreen \& Shehata: Carbetocin versus oxytocin for prevention of postpartum hemorrhage after 
vaginal delivery in high risk women; $\mathrm{J}$ Matern Fetal Neonatal Med,2015; 29(4): 532-536

26. Prevention and management of postpartum haemorrhage, Royal College of Obstetricians and Gynaecologists, Green-top Guideline No. 52, Minor revisions November 2009 and April 2011

27. The Prevention and Management of Postpartum Haemorrhage: Report of Technical Working Group, Geneva 3-6 July 1989. Geneva: World Health Organization, 1990

28. Bais JM, Eskes M, Pel M, Bonsel GJ, Bleker OP. Postpartum haemorrhage in nulliparous women: incidence and risk factors in low and high risk women. A Dutch population-based cohort study .Eur J Obstet Gynecol Reprod Biol. 2004; 115:166-72

29. Dutch Association of Obstetrics and Gynaecology (NVOG) .Guideline postpartum haemorrhage. 2012;1-9.

30. Chandhiok N, Dhillon BS, Datey S, Mathur A, Saxena NC .Oral misoprostol for prevention of postpartum haemorrhage by paramedical workers in India. Int J GynaecolObstet 2006; 92:170-75

31. Sheehan SR, Montgomery AA, Carey M, et al. Oxytocin bolus versus oxytocin bolus and infusion for control of blood loss at elective caesarean section: double blind, placebo controlled, randomised trial . The BMJ. 2011 August $1 ; 343$ 